\title{
¿Una nueva iconografía? Santa Teresa en el arte novohispano ${ }^{\top}$ \\ A New lconography? St. Teresa in New Spanish Art
}

\section{Luis Javier Cuesta / Alejandro Hernández García}

Universidad Iberoamericana / UNAM

MÉXICO

luis.cuesta@ibero.mx / condedeselvanevada@gmail.com

[Hipogrifo, (issn: 2328-1308), 4.2, 2016, pp. 7-18]

Recibido: 04-02-2016 / Aceptado: 17-02-2016

DOI: http://dx.doi.org/10.13035/H.2016.04.02.02

Resumen. Analizamos algunos textos y algunas obras que representan a santa Teresa de Ávila, dentro del corpus de sermones y obras artísticas de la Nueva España, para investigar su cercanía o su singularidad respecto a la metrópoli. Confrontamos textos e imágenes para enriquecer la lectura y mostrar algunos repertorios artísticos donde se inscribió la figura de la santa reformadora del Carmelo.

Palabras clave. Santa Teresa, arte novohispano, iconografía, escultura, pintura, canonización, beatificación, sermones, imago.

Abstract. We analyze some works of art representing St. Teresa of Ávila, within the corpus of sermons, paintings and sculptures of the New Spain, to investigate its proximity or their uniqueness regarding the metropolis. We confront texts and images to enrich reading and show some artistic repertoires where he enrolled to the figure of the holy reformer of Carmel.

Keywords. St. Teresa, New Spain, Art, Iconography, Sculpture, Painting, Imago, Canonization, Beatification, Sermons.

1. Hoy, estudios básicos sobre Santa Teresa en Nueva España, deberían ser los de Christopher C. Wilson, 1998; y Elisa Vargaslugo y José Guadalupe Victoria, 1985-1994. 


\section{INTRODUCCIÓN. LA CREACIÓN DE LA ICONOGRAFÍA TERESIANA TRAS SU BEATIFICA- CIÓN (1614) Y CANONIZACIÓN (1622). EL IMPACTO EN NUEVA ESPAÑA}

La beatificación de santa Teresa en $1614^{2}$ trajo consigo, como era costumbre, la primera aparición de series grabadas acompañando a las hagiografías que relataban la vida de la nueva beata. Dejando de lado la famosa vera effiggies de fray Juan de la Miseria de 1576 (fig. 1) (modelo fundamental para todos los retratos posteriores), como bien ha estudiado María José Pinilla, la primera de esas series fue la de Cornelius Galle y Adrián Collaert (Amberes, 1613) que acompañaba la Vita Beatae Virginis Teresiae a lesu, que, como nos recuerda Moreno Cuadro: «tuvo una amplia repercusión artística en América, recordar las cinco series pintadas derivadas de ella en His- Fig. 1. Fray Juan de la Miseria, Retrato de

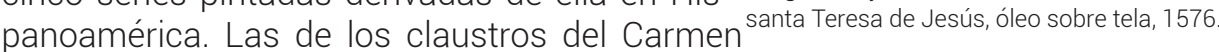
alto de Quito del siglo XVIII (Ecuador) - la del claustro bajo, con pocos lienzos, y la del claustro alto en pinturas murales del XVIII (Meboldk, 1985: 54-107)- y las tres series del siglo XVII que presentan un mejor estado de conservación y mayor interés, la pintada por José Espinoza de los Monteros para el convento de Santa Teresa del Cuzco (Perú), en 1682, y las dos series de Santiago de Chile fechadas en torno a 1691, cuando ingresa en el convento Ana de Jesús, que las entrega como dote -Mesa-Gisbert, 1962-»³, (aunque en realidad y como bien menciona Pinilla, el proceso es al contrario, como era usual, más que surgir de la beatificación como consecuencia de esta, el libro fue encargado ya desde 1611 para apoyar la causa4).

El proceso de introducir a la nueva beata en las prácticas devocionales en todos los reinos hispánicos tuvo como uno de sus hitos fundamentales las celebraciones que se efectuaron en honor de la beatificación a lo largo de todas las ciudades destacadas de los reinos hispánicos en $1614^{5}$. Esas fiestas religiosas y los textos de sermones y oraciones que se compusieron en homenaje a Teresa tuvieron como efecto que su imagen simbólica llegase a los corazones de todos los estamentos sociales al mismo tiempo, o antes incluso de que las imágenes artísticas fueran conocidas por todos.

La ciudad de México, como una de las capitales más importantes de los reinos americanos, no podía quedarse atrás en la celebración de este acontecimiento y conservamos al menos dos sermones impresos que conmemoran la beatificación

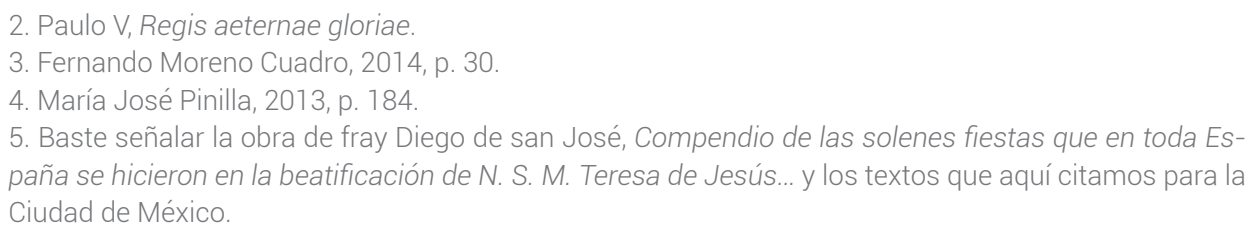


de Santa Teresa en 1614: el dominico fray Luis de Vallejo ${ }^{6}$ y el arzobispo Juan Pérez de la Serna ${ }^{7}$, pronunciaron dichos sermones con apenas seis días de diferencia en el convento de los Carmelitas descalzos de la ciudad en el marco del novenario que siguió a las fiestas de la beatificación (Francisco de Solano cita un «Sermón del Padre Guillermo de los Ríos, rector del colegio de la Compañía de Jesús» que hasta ahora, y desafortunadamente, no hemos conseguido encontrar) ${ }^{8}$.

No podemos soslayar, en este sentido, el hecho de que el arzobispo será instrumental, apenas dos años después, en la fundación del convento femenino de Carmelitas descalzas de la ciudad de México:

Con el apoyo decidido del Arzobispo Juan Pérez de la Serna, dos monjas del Real Convento de Jesús María, Sor Inés de la Cruz y Sor Mariana de la Encarnación, salieron un día del año de 1616 a fundar el convento y el templo de San José de Carmelitas descalzas (mejor conocido como Santa Teresa la Antigua) ${ }^{9}$.

\section{LA ICONOGRAFÍA DE SANTA TERESA EN EL ARTE NOVOHISPANO: TEXTOS E IMAGO}

Nos gustaría utilizar esos dos sermones para intentar demostrar como en el marco de las políticas religiosas de la época, la retórica presente en estas piezas de la homilética novohispana del XVII contribuían a fijar una serie de imágenes en la conciencia colectiva que trabajaban en común/reforzaban/precedían a las imágenes artísticas que en los siguientes años los artistas novohispanos producirían de manera extensiva. En cierto sentido, las figuras retóricas que el dominico y el arzobispo utilizan en sus sermones serían casi equivalentes a la circulación de estampas a la hora de «fijar» las iconografías novohispanas de Teresa.

Curiosamente ambos sermones eligen identificar a la abulense con el «typus» veterotestamentario de Deborah (Jueces), a la orden del Carmelo con un enjambre de abejas e insisten en la parábola de las vírgenes sabias y necias:

A cual de las dos clases señaladas en nuestro Evangelio de vírgenes prudentes e imprudentes, habemos de reducir a nuestra gloriosa Virgen Teresa por que si en la de las prudentes se colocan las que con luces salieron a recibir a el esposo cierto es que nuestra Teresa de Jesús est virgo Sapiens, una de numero prudentum. Que es Virgen sabia y una del número de las sabias... ${ }^{10}$

Nos detenemos en la ultima frase porque nos da pie para una primera reflexión sobre la iconografía de Teresa, en concreto la imagen de la santa como escritora/ doctora (aunque no hay que olvidar que Santa Teresa no fue declarada como Doc-

6. Luis Vallejo, Sermón que predicó..

7. Juan Pérez de la Serna, Sermón que el ilustrísimo...

8. Francisco de Solano, 1994, p. 1894. El texto es: Sermón que predicó el Padre Guillermo de los Rios, rector del colegio de la Compañía de Jesús de esta ciudad de México en las fiestas que se celebraron en la canonización de la gloriosa virgen Santa Teresa de Jesús, México, Juan de Alcazar, 1623.

9. Saucedo Zarco, 1989, p. 107

10. Pérez de la Serna, Sermón que el ilustrísimo..., p. 3. Las cursivas son nuestras. 
tora de la Iglesia universal hasta tan tarde como 1970, ya en los siglos XVII y XVIII empezarían a aparecer bonetes sobre la mesa de escribir en algunas imágenes como símbolo de su calidad de doctora).

Como dice Pinilla fue: «sin duda el (tema) más conocido de la iconografía teresiana, (y) surgió a partir de la incorporación de los útiles de escritora - pluma, tintero y libro- a la vera effigie» ${ }^{11}$. La iconografía se iría consolidando a través de la placa 23 de la Vita B. Virginis Teresiae a lesu de Collaert y Galle, del grabado conmemorativo de la beatificación de Francisco de Villamena (Instituto Histórico Teresianum de Roma, 1614); o de la estampa de Mattheo Greuter, impresa para la canonización (Roma, 1622). Que todas esas imágenes coincidían con las ideas del arzobispo o del dominico Vallejo lo demuestran la cantidad de citas a ese respecto que podemos encontrar en estos dos sermones:

Nuestra Gloriosa Virgen Teresa con su sabiduría confundió y convenció no a los sabios ignorantes de la gentilidad, sino a los mas despabilados y doctos Maestros y Catedráticos de las escuelas de los católicos [...] que está también señalada y colocada con borla de Doctor entre los Doctores santos de la Iglesia... ${ }^{12}$

También tiene su cátedra de sabiduría, pero es de mayores, es de prima... ${ }^{13}$

No nos faltan imágenes novohispanas sobre este tema, algunas muy divulgadas como la muy temprana de Luis Xuárez del Museo de Guadalajara que se ha querido situar incluso antes de la beatificación de 1614, pero otras aún poco conocidas, como la Santa Teresa anónima, de la colección del Monasterio de Santa Teresa la Nueva, México (fig. 2); o el óleo Santa Teresa de Jesús abanderada, de la colección del Convento de Carmelitas Descalzas del Santísimo Sacramento y Santa María de Guadalupe, de Ecatepec, (Estado de México) (fig. 3).

Y es que como predicaba Juan Pérez de la Serna:

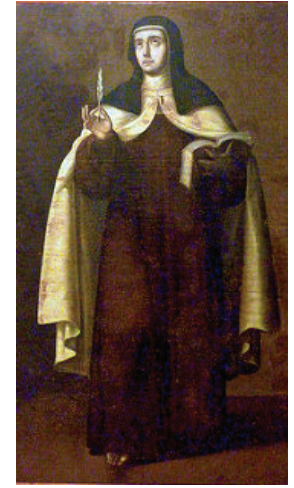

Fig. 2. Santa Teresa de Jesús, óleo sobre tela autor desconocido, siglo XVIII. Colección del convento de Carmelitas Descalzas de Santa Teresa la Nueva, Ciudad de México

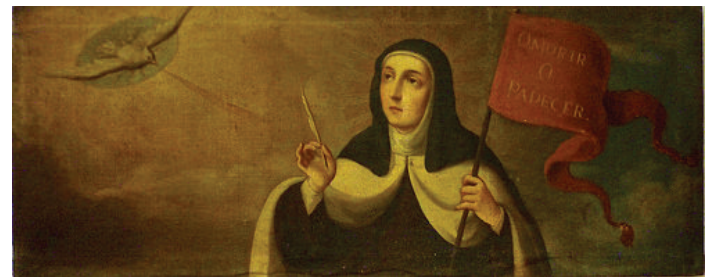

Fig. 3. Santa Teresa de Jesús abanderada, óleo sobre tela, autor desconocido, siglo XVIII. Colección del convento de Carmelitas Descalzas del Santísimo Sacramento y Santa María de Guadalupe, Ecatepec, México.

11. Pinilla Martín, 2012, p. 639.

12. Pérez de la Serna, Sermón que el ilustrísimo..., p. 8.

13. Vallejo, p. 9. 
Quién viera a una mujer humilde, encogida, envuelta en una rota capa de basto sayal [...] mujer de pocas razones y palabras, nada bachillera, ni presumida, pero era valiente y poderosa con el caudal de su sabiduría... ${ }^{14}$

La historia de aquella profetisa que, bajo la palmera de Déborah, impartió justicia al pueblo de Israel, sirvió de piedra angular para desplantar la estatua de Teresa como doctora de la Iglesia, reformadora de la conducta del Carmelo y juez entre los hombres.

La imagen de la santa de Ávila y sus obras, permitieron la escasa representación de mujeres combinando actividades intelectivas y domésticas en el virreinato. El modelo se repitió durante más de un siglo dentro y fuera de los claustros femeninos novohispanos, junto a la imagen de santa Ana maestra o santa Catarina en el torneo filosófico, se convirtieron en ejemplo y bandera para las religiosas, beatas o seglares que querían empuñar la pluma, siempre invocando la sabiduría del Espíritu Santo.

Pero fray Luis Vallejo fue quizá más alto en su prédica y comparó a Teresa con Déborah, ubicando en el medio a María. La profetisa era fuente de justicia, la Virgen del Carmen era fuente de vida y la monja reformadora daba nueva vida, nueva vara de justicia y nuevas obras a la cristiandad. Lo que hacía singular a Teresa era su «victoria ganada a los brazos», una lucha página tras página, confesor tras confesor y fundación tras fundación que la convirtió en victoriosa escuela de sabiduría. Imágenes de religiosas que invocaban la sabiduría fueron posibles gracias a Teresa. Tomemos por ejemplo un grabado de sor Hipólita de Jesús y Rocaberti ante Cristo y frente a sus obras escritas, de la Vida de Hipólita de Jesús y Rocaberti, publicada en Valencia en 1679 (un ejemplar se encuentra hoy en la Biblioteca Burgoa de Oaxaca) (fig. 4), y pensemos que sólo el ejemplo de Santa Teresa de Ávila hizo plausibles imágenes como esa, como demuestra una escultura de autor desconocido, probablemente guatemalteca del siglo XVII que guarda el exconvento del Carmen, Oaxaca (actual arzobispado) (fig. 5).

Continuando en este tenor, otra de las imágenes que encontraremos con asiduidad y que podríamos considerar como paradigmática en la vida de santa Teresa es

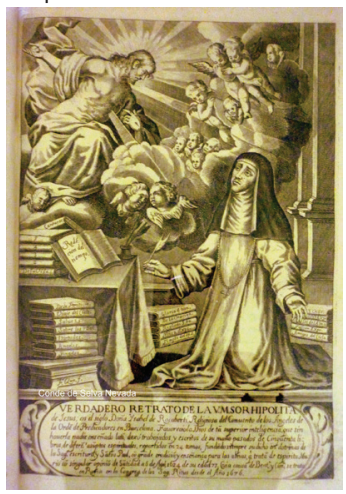

Fig. 4. Grabado de sor Hipólita de Jesús y Rocaberti ante Cristo y frente a sus obras escritas. Vida de Hipólita de Jesús y Rocaberti, Valencia, 1679. Biblioteca fray Francisco de Burgoa, Oaxaca, México

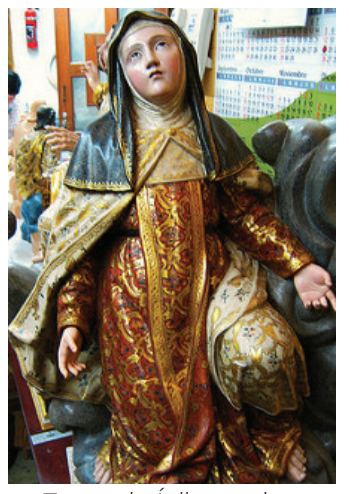

Fig. 5. Santa Teresa de Ávila, escultura encarnada, dorada y policromada, autor desconocido, Escuela Guatemalteca, siglo XVII. Colección del exconvento del Carmen, hoy Arzobispado, Oaxaca, México.

14. Pérez de la Serna, Sermón que el ilustrísimo..., p. 8. 
la Trasverberación (tal y como narra ella misma) ${ }^{15}$. Es sin ningún lugar a dudas, la imagen más difundida y reproducida por parte de los artistas y grabadores en todo el panorama de la vida de la santa española. El hecho de que el relato se encontrase presente en la Bula de canonización así como su presencia en el grabado oficial surgido de esa ceremonia, sin duda contribuyeron a esa difusión tan importante, pero sobre todo tan rápida ${ }^{16}$.

Los sermones de Pérez de la Serna y Vallejo insisten en la figura de Teresa como nueva Débora, juez(a) del pueblo de Israel y vencedora de sus enemigos. Las contrapartes masculinas de ese relato veterotestamentario son, en un caso, Lepidot, y en otro Barac. Ambos eclesiásticos interpretaron el nombre de dichos personajes como figuras ígneas: llamas, antorchas o fuego. La mancuerna establecida entre Débora y Lepidot o Débora y Barac constituían entonces, siempre en nuestra opinión, un excelente pretexto para hablar de la relación entre la santa de Ávila y sus compañeros de armas en la reforma carmelitana, pero también podrían ¿por qué no?, proporcionarnos pistas para la representación de la transverberación de Teresa. Desde que se abre la estampa de Collaert para la Vita Beatae Virginis Teresiae a lesu, el tema tendrá una inmensa repercusión dentro y fuera de los claustros carmelitanos.

Pero, como leemos también en esos mismos sermones, no podría considerarse esa «prefiguración veterotestamentaria», como el único testigo de la difusión de su presencia en los relatos orales y escritos, en los «textos» en el sentido más amplio de la palabra que contribuían al conocimiento de la vida de santa Teresa. Efectivamente, Vallejo se refiere al arrebato también de una forma mucho más directa y nos atrevemos a decir incluso «visual»:

Le debió de pedir que fuese a atravesarle el corazón con aquella arma, para que así quedase inflamada y hecha un fuego [...] id Ángel y atravesad el corazón de aquella mujer, sienta lo que yo siento, abrásese en celo de la honra de Dios [...] Y así lo hizo el Ángel con espada o lanza de fuego estando orando le abrió el pecho y le abrazó el corazón... ${ }^{17}$

15. «Quiso el Señor que viese aquí algunas veces esta visión: veía un ángel cabe mí hacia el lado izquierdo, en forma corporal, lo que no suelo ver sino por maravilla; aunque muchas veces se me representan ángeles, es sin verlos, sino como la visión pasada que dije primero. En esta visión quiso el Señor le viese así: no era grande, sino pequeño, hermoso mucho, el rostro tan encendido que parecía de los ángeles muy subidos que parecen todos se abrasan. Deben ser los que llaman querubines, que los nombres no me los dicen; mas bien veo que en el cielo hay tanta diferencia de unos ángeles a otros y de otros a otros, que no lo sabría decir. Veíale en las manos un dardo de oro largo, y al fin del hierro me parecía tener un poco de fuego. Este me parecía meter por el corazón algunas veces y que me llegaba a las entrañas. Al sacarle, me parecía las llevaba consigo, y me dejaba toda abrasada en amor grande de Dios. Era tan grande el dolor, que me hacía dar aquellos quejidos, y tan excesiva la suavidad que me pone este grandísimo dolor, que no hay desear que se quite, ni se contenta el alma con menos que Dios. No es dolor corporal sino espiritual, aunque no deja de participar el cuerpo algo, y aun harto. Es un requiebro tan suave que pasa entre el alma y Dios, que suplico yo a su bondad lo dé a gustar a quien pensare que miento» (Teresa de Jesús, Vida, pp. 157-158).

16. Pinilla, 2012, p. 747

17. Luis Vallejo, Sermón que predicó..., p. 6. 
En el caso de la pintura novohispana, y como dice Christopher Wilson ${ }^{18}$, el tema se popularizó mucho durante el siglo XVII. Los grabados más utilizados por parte de los artistas fueron, sin duda, el ya citado de Collaert en 1613, o el de Wierix de cir-

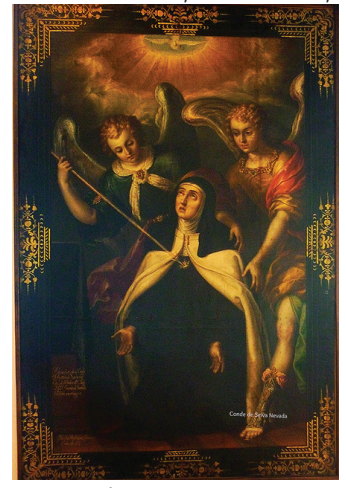

Fig. 6. Transverberación de Santa Teresa de Ávila, Nicolás Rodríguez Xuárez, óleo sobre tela 1692. Museo Nacional del Virreinato, México.

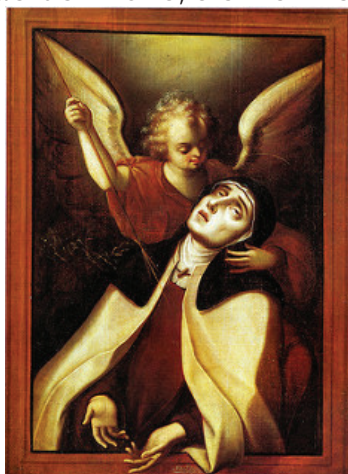

Fig. 7. Transverberación de santa Teresa de Jesús, óleo sobre tela, Nicolás Rodríguez Xuárez, siglo XVIII. Colección del Museo de la Basílica de Guadalupe, Ciudad de México.

ca 1622 que siguen con más o menos fidelidad Alonso López de Herrera en el óleo de la colección Pérez Salazar (que ya publicó Christopher Wilson), y Nicolás Rodríguez Xuárez en dos lienzos del Museo Nacional del Virreinato (fig. 6) y de la Basílica de Guadalupe (fig. 7) respectivamente. Notable, sin duda, resulta el conjunto de obras que los pintores de la familia Xuárez dedicaron al tema, y aunque en algunos casos se muestran fieles a las estampas que podríamos considerar "canónicas», en otros se apartan hacia una subvariante iconográfica que Pinilla denomina como «con el Niño Jesús» (tal vez sería más correcto con la Sagrada Familia) ${ }^{19}$, y Moreno Cuadro como "Transverberación con las dos trinidades» ${ }^{20}$. Podríamos pensar en principio que el éxito de esta iconografía entre los pintores novohispanos, véanse por ejemplo las versiones de Juan Rodríguez Xuárez y de un anónimo seguidor de su círculo en sendas colecciones privadas, se debía por un lado a la difusión del culto a la familia de Belén (no olvidemos la importancia de san José en la devoción teresiana), y por otro a un creciente interés en la alusión al misterio trinitario. En ese mismo tenor tampoco nos resistimos a citar la aparición de temas relacionados con la visión de la Santísima Trinidad por parte de santa Teresa y san Juan de la Cruz a raíz de la beatificación del último en 1675, como la pintura que representa a ambos contemplando el misterio de la Trinidad, en el locutorio del convento de la Encarnación de Ávila, que se guarda en el Museo Nacional de Historia, en Chapul-

18. «Like their counterparts in Europe, many of the greatest painters of New Spain also took up their brushes to paint representations of the Transverberation. Teresa's image was a favorite one in the viceroyalty, featured in the decoration of many churches, convents, and monasteries, especially those associated with the reformed Order she had founded, the Discalced Carmelites. Beyond the Virgin Mary, few other female subjects were so often depicted in Latin American art of the seventeenth and eighteenth centuries as Teresa of Ávila, and the Transverberation was among the most popular Teresian themes treated by Mexican painters» (Wilson, 1999, p. 212).

19. Pinilla, 2012, p. 753

20. Moreno Cuadro, 2012. 
tepec, y que sigue el grabado del francés Messager de fines del XVII, que probablemente también inspiró el óleo setecentista del pintor Acosta, que se conserva en el Museo del Carmen de San Ángel (fig. 8).

Extraordinaria también, al menos desde un punto de vista estrictamente iconográfico, es la Transverberación que pinta Correa para la Capilla de santa Catarina, en la Iglesia del Convento de santo Tomás, Ávila, España, siguiendo fielmente el hermoso grabado de Quelinus y Colin y que ya ha sido estudiada por Vargaslugo y

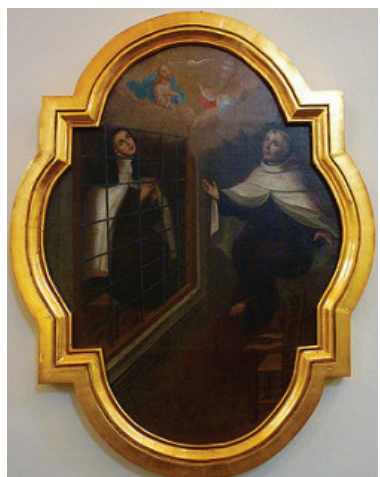

Fig. 8. Santa Teresa de Jesús y san Juan de la Cruz levitando, Acosta, óleo sobre tabla, siglo XVIII. Colección del Museo del Carmen, Ciudad de México.

\section{Christopher Wilson.}

Interesante es la Trasverberación del círculo de Villalpando que guarda la Pinacoteca de La Profesa en la que la santa aparece también como doctora. Y que nos permite recordar cómo Cristóbal de Villalpando retomará otro importante pasaje de la vida de la santa, otra de sus gracias espirituales, cuando recibe de la Virgen y san José un collar y un velo. Villalpando reproduce dicha escena en el famoso lienzo que se guarda también en la Pinacoteca de La Profesa. La fuente de esta escena es, probablemente, el ya para entonces muy conocido relieve tallado por Gregorio Fernández para el claustro carmelita de Ávila hacia 1648, sin embargo Villalpando introducirá sobre este modelo un par de variantes: la trinidad celeste está incompleta, sólo aparece el Espíritu Santo, y las manos de Teresa no se juntan en gesto de oración. La pintura novohispana a que nos referimos muestra a la santa abulense enseñando las palmas de las manos en gesto de entrega, muy cercano al de la Transverberación de Nicolás Rodríguez Xuárez que se conserva en los claustros de Tepotzotlán, mencionado momentos atrás. El gesto además se proyecta hacia el espectador, no así la mirada de la santa, que apunta hacia el cielo, como convidando a un personaje ausente. ¿Será la representación más vívida del abandono de la voluntad propia? Quizá. «Dióseme a entender, que estaba ya limpia de mis pecados», cuenta Teresa en el Libro de su Vida ${ }^{21}$. Para hacernos una idea de la originalidad de la escena de Villalpando podemos compararla con la de Luis Xuá-

21. Teresa de Jesús, Libro de su vida, p. 261. 
rez en la parroquia de la Natividad de Atlixco que sigue con mucha más fidelidad la estampa de Collaert y Galle22.

Pero para continuar hablando de las gracias espirituales recibidas por la santa, regresemos por un instante a nuestros sermones. El arzobispo Pérez de la Serna se refiere a otro de los momentos fundamentales de la vida de santa Teresa cuando menciona sus desposorios místicos:

Pues si nos acordamos del espiritual desposorio tantas veces repetido en este lugar, que Cristo nuestro señor celebró co(n) nuestra gloriosa Virgen Teresa, donándole por arras, prendas y señal de amor un clavo de su pasión: hallaremos que le viene muy a medida a la esposa de Cristo, Teresa de Jesús...23

El arzobispo tenía muy clara la imagen en su mente, probablemente debido a la lectura cuidadosa de la descripción de la escena en las Cuentas de Conciencia de santa Teresa ${ }^{24}$, mucho antes que tuviéramos constancia visual de la historia en la pintura novohispana como, por ejemplo, en la magnífica pintura de Juan Correa, ya de fines del XVII, del Museo de las Intervenciones, que formó parte sin duda de un retablo de tema teresiano.

Con la beatificación en 1622 y canonización en 1669 de Pedro de Alcántara, los carmelitas y los descalzos franciscanos impulsaron las escenas de hermandad entre Teresa y Pedro. Como recuerda Salvador Andrés Ordax ${ }^{25}$, hubo diversas alusiones a ambos santos en iglesias carmelitas y dieguinas. En Nueva España se popularizó el grabado madrileño de Pedro de Villafranca Malagón.

Un óleo que conservan los frailes dieguinos del antiguo convento de san Ildefonso de Oaxaca resulta verdaderamente interesante (fig. 9); el domingo 18 de octubre de 1562 san Pedro de Alcántara murió y santa Teresa de Ávila pudo verlo subir a la Gloria, en un altar efímero de la iglesia matritense de san Felipe, levantado en las fiestas por la canonización del alcantarino, se describió el siguiente conjunto escultórico: «Se ofrecía a la vista un bufete con rica sobremesa y recado de escribir, y allí junto dos figuras de relieve entero: una de Santa Teresa de Jesús que, asentada y con la pluma en la mano, se quedaba admirada por ver del otro lado a San Pedro de Alcántara, que sobre una nube la visitaba y aparecía» ${ }^{26}$. La proximidad entre este

22. «En el Monasterio de Nuestra Señora de Valdeflores de Viveiro (Lugo) se encuentra una Visión de Santa Teresa de finales del siglo XVII o principios del siglo XVIII. La santa aparece en el centro de la composición, vestida con el hábito de carmelita, arrodillada. Sobre ella se encuentran la Virgen y San José, que le colocan una guirnalda de flores. En el suelo hay un libro abierto, y rodeando a los personajes cabezas de querubines...» (Barea Azcón, 2008-2009, pp. 40-41). No hemos conseguido una fotografía de la obra, pero por la descripción es evidente que se trata de una imagen de la Imposición del velo y el collar

23. Pérez de la Serna, Sermón que el ilustrísimo..., p. 3.

24. «[Cristo] representóseme por visión imaginaria como otras veces, muy en lo interior, y diome su mano derecha y dijome: mira este clavo, que es señal que serás mi esposa desde hoy; hasta ahora no lo habías merecido; de aquí adelante, no sólo como Criador y como Rey y tu Dios mirarás mi honra, sino como verdadera esposa mía» (Teresa de Jesús, Cuentas de Conciencia, p. 605).

25. Salvador Andrés Ordax, 1982

26. Ordax, 1982, p. 319 


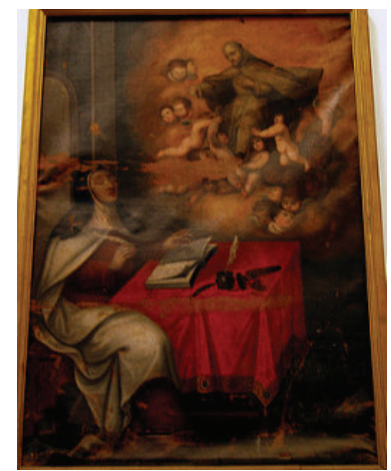

Fig. 9. Aparición de san Pedro de Alcántara a santa Teresa de Jesús, óleo sobre tela, autor desconocido, ¿siglo XVII? Colección del convento de franciscanos descalzos de San Ildefonso, Ciudad de Oaxaca.

altar festivo y el cuadro oaxaqueño, es tanto interesante cuanto enigmática. ¿Sería un calco de las descripciones de fiesta madrileñas?

\section{CONCLUSIONES}

No queremos terminar sin referirnos a una cita más en el sermón del arzobispo Pérez de la Serna sobre la igualdad en la orden de carmelitas descalzas:

¿En el regalo de la comida no hay igualdad? [...] tan poco y tan malo es lo que come el Provincial, como lo que fe da al lego, no hay mas regalo para el superior, que para el súbdito [...] porque como todo lo que tienen, es de todos y nada es de ninguno...27

No nos resistimos a conectar este concepto con el lienzo anónimo del siglo XVIII del Museo de Guadalajara donde aparece santa Teresa sentada a la mesa con Cristo ofreciéndole un trozo de pan (estampa de Cornelis van Merlen,1666-1733). Por supuesto podemos darle a la imagen un significado de alegoría eucarística considerando a Cristo Sacerdote, e insistiendo en la idea tridentina de la comunión frecuente ${ }^{28}$, ante el creciente jansenismo que propugnaba exactamente lo contrario; pero no nos parece pueril tampoco la posibilidad de verlo como esa igualdad en la orden a la que aludía el arzobispo ya en 1614.

27. Pérez de la Serna, Sermón que el ilustrísimo..., p. 5.

28. Moreno Cuadro, 2014, pp. 39-40. Como dice el autor, la comida mística es recogida ya por el padre Diego de Yepes en 1606: Yepes (1606) - «Y otra vez (como ella dejó escrito en un papel) le hizo el Señor otro regalado favor, estando una vez (dice) con la pena que traigo de que estoy ausente de Dios, y estos días había sido bien grande, que parecía no la podía sufrir, y habiendo estado así harto fatigada, vi que era tarde para hacer colación y no podía, y a causa de los vómitos háceme mucha flaqueza, no la hacer un rato antes, y así con harta fuerza, puse el pan delante para hacer a comerlo, y luego se me representó allí Cristo, y parecía que me partía el pan, y me lo ponía en la boca, y díjome: "come hija, y pasa como pudieres, bien veo lo que padeces, más esto te conviene ahora"» (Moreno Cuadro, 2014, pp. 39-40). 
Un ejemplo más de lo difícil que es, en ocasiones, discernir entre la prelación texto e imagen en la formación de, valga la redundancia, un imaginario colectivo sobre una figura como la de Teresa de Jesús.

Y es que como colofón, nos gustaría presentar del antiguo convento carmelita de san Joaquín, de la Ciudad de México, un óleo que representa a la santa de Ávila con la pluma, la mesa donde deposita el bonete y sus obras y con la mano izquierda sosteniendo una bandera (fig. 10). Parecería una novedad que el pintor la coloque de pie sobre un orbe, casi con gesto circense, ya que ni en las estampas aquí mencionadas, ni en los textos que hemos citado aparece una imagen como ésta.

Concluimos así defendiendo que las fechas de los textos y de las obras nos indican que la carrera por representar a la nueva santa, se reflejó en la Nueva España de manera singular, que se acercaron los artistas a los modelos y que escucharon

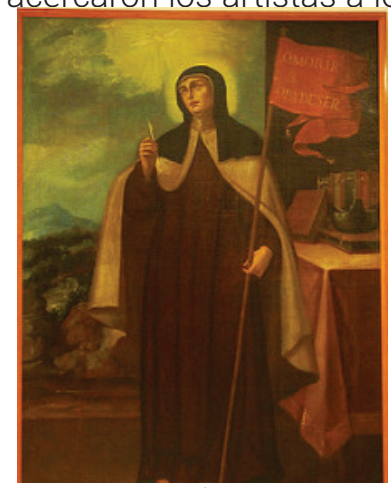

Fig. 10. Santa Teresa de Ávila, óleo sobre tela, autor desconocido, siglo XVII. Colección del convento de San Joaquín, Ciudad de México.

las descripciones o recibieron encomiendas de clientes que deseaban pinturas y esculturas de Teresa de Jesús. Al ir desempolvando viejas bibliotecas y antiguos repositorios, lograremos ratificar si hubo una nueva iconografía, o antes al contrario una producción artística apegada a los modelos que llegaron de ultramar.

\section{BIBLIOGRAFÍA}

Barea Azcón, Patricia, «Pintura novohispana en Galicia», Abrente. Boletín de la Real Academia Gallega de Bellas Artes de Nuestra Señora del Rosario, 40-41, 2008-2009, pp. 347-362.

Moreno Cuadro, Fernando, «La serie de las Transverberaciones de santa Teresa con las dos Trinidades derivada de Wierix. Acerca de una pintura de Francisco Rizi», Goya. Revista de Arte, 341, 2012, pp. 312-323.

Moreno Cuadro, Fernando, «lconografía de los testigos de los procesos teresianos. A propósito de Adrián Collaert y la escenografía de la capilla Cornaro», Archivo Español de Arte, 345, 2014, pp. 29-44. 
Ordax, Salvador Andrés, «lconografía teresiano-alcantarina», Boletín del Seminario de Estudios de Arte y Arqueología, 48, 1982, 301-326.

Paulo V, Regis aeternae gloriae, Roma, 1614. Disponible en: <http://albadetormes. $\mathrm{com} /$ portal/p_20_contenedor $1 . j s p ?$ seccion=s_fdes_d1_v1.jsp\&contenido=19 $213 \&$ tipo $=6 \&$ nivel $=1400 \&$ layout $=$ p_20_contenedor $1 . j s p \&$ codResi $=1 \&$ languag e=es\&codMenu=10619\&codMenuPN=4\&codMenuSN=10543> [10/08/2016].

Pérez de la Serna, Juan, Sermón que el ilustrísimo [...] Arzobispo de México predicó, celebrando misa de pontifical, en el convento de los religiosos carmelitas descalzos de dicha ciudad [...] Día octavo de las fiestas que a la beatificación de la santa virgen Teresa de Jesús..., México, imprenta de la Viuda de Diego López Dávalos, 1614.

Pinilla Martín, María José, Iconografía de santa Teresa de Jesús, Valladolid, Universidad de Valladolid, tesis doctoral, 2012.

Pinilla Martín, María José, «Dos "Vidas gráficas" de santa Teresa de Jesús: Amberes 1613 y Roma 1655», Boletín del Seminario de Estudios sobre Arte, 79, 2013, pp. 183-202.

Saucedo Zarco, Carmen, «El pintor Luis Juárez: un trabajo para santa Teresa la Antigua», Relaciones. Estudios de Historia y Sociedad, 39, 1989, pp. 107-114.

Sifuentes Solís, Marco Alejandro, «La sermonaria novohispana y su influencia en la arquitectura religiosa de Aguascalientes: prácticas de lectura y simbolismo mariano en el Camarín de la Virgen (1792-1797)», Revista de Historia Iberoamericana, 2, 2010, pp. 90-123.

Solano, Francisco de, Las voces de la ciudad. México a través de sus impresos (1539-1821), Madrid, CSIC, 1994.

Teresa de Jesús, santa, Cuentas de conciencia, Madrid, Biblioteca de Autores Cristianos, 1954.

Teresa de Jesús, santa, Libro de su vida, México, Porrúa, 1975.

Vallejo, Luis, fray, OP, Sermón que predicó [...] a la beatificación de la bienaventurada madre santa Teresa de Jesús..., México, imprenta de la Viuda de Diego López Dávalos, 1614.

Vargaslugo, Elisa y José Guadalupe Victoria, «Theresia Magna», en Juan Correa: su vida y su obra, México, UNAM, 1985-1994, pp. 417-452.

Wilson, Christopher C., Mother, Missionary, Martyr: St. Teresa of Ávila in Mexican Colonial Art, Ann Arbor, UMI, 1998.

Wilson, Christopher C., «Saint Teresa of Ávila's Martyrodom: Images of Her Transververation in Mexican Colonial Painting», Anales del Instituto de Investigaciones Estéticas, 74-75, 1999, pp. 211-233. 